\title{
Werner Herzog, documentales de viaje: Fata Morgana, La Soufrière, A la espera de una catástrofe inevitable, Wodaabe, Pastores del sol, Jag Mandir
}

\section{Gonçalves, Igor Dimitri}

Resumen: Cuatro películas del director alemán Werner Herzog son analizadas por sus características comunes en cuanto ensayos-fílmicos de viaje. Estas obras, menos conocidas, medio metrajes, que supuestamente arriesgan menos, o por otras palabras, de búsqueda física de creación documental en el acto mismo de observación, sirven justamente para ilustrar su recorrido personal por las formas de hacer documental más "convencionales".

Este articulo sostiene qué: por un lado, en estas películas el autor hace uso de una puesta en escena que toma del naturalismo de Paul Rotha y su dispositivo romántico, entre otros autores; y por el otro, qué lo que les

Cuadernos del Centro de Estudios de Diseño y Comunicación Nº 62

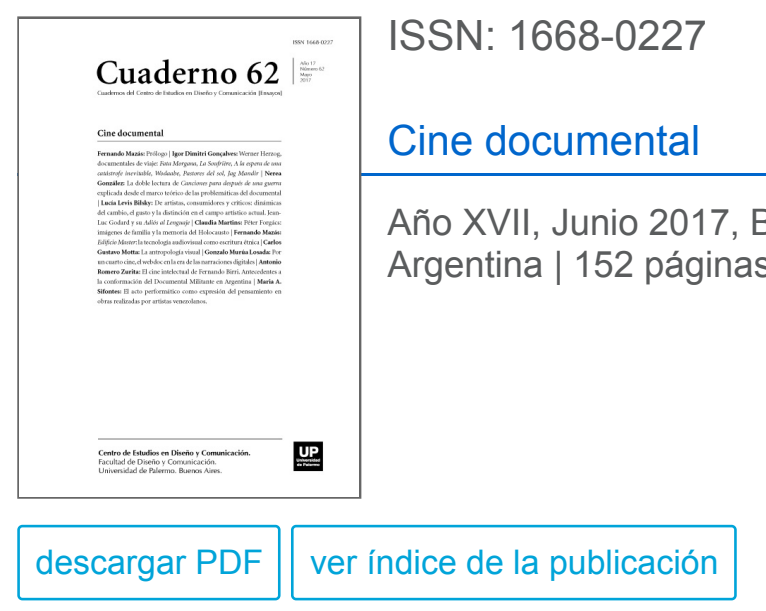

Ver todos los libros de la publicación

compartir en Facebook añade Herzog es necesariamente lo qué las aleja de una definición contenedora. Es decir, para nosotros, el valor de estos ensayos fílmicos reside en el uso de las herramientas clásicas que son resinificadas por la marca autoral. En el presente articulo se reflexiona sobre la dificultad en determinar modalidades y cerrar películas en definiciones, en el cine documental, partiendo del estudio de casos de un recorte de la filmografía de un autor.

Palabras clave: Werner Herzog - ensayos fílmicos de viaje - Fata Morgana - La Soufrière - Wodaabe - Jag Mandir.

$\left(^{*}\right)$ Post-grado en Media y Periodismo por la Universidade do Porto, Portugal. Actualmente frecuenta la Maestría en Cine Documental de la Universidad del Cine, Buenos Aires.

Introducción 
A lo largo del trabajo me propongo analizar cronológicamente algunas de las películas documentales realizadas por el director Werner Herzog, entre un periodo que va desde 1971 a 1991. Son ellas: Fata Morgana (1971), La Soufrière - A la espera de una catástrofe inevitable (1977), Wodaabe - Pastores del sol (1989) y Jag Mandir (1991). Estas comparten elementos característicos de un cine que en este trabajo llamo "de viaje", a través de los cuales las relaciono. Analizaré las cuatro películas del corpus en busca de un estilo común entre ellas, al mismo tiempo que reconozco la dificultad en concebir la obra de este autor dentro de un espectro de definiciones cerradas. Lo que intento es realzar los dispositivos propuestos en estas películas, en búsqueda de elementos de una firma herzogiana1. Esta sería caracterizada desde ya, tanto por la distancia conceptual entre sus películas a lo largo de su carrera, como también por una heterogeneidad de su obra. Este es un autor transversal a los "géneros", no distinguiendo él mismo entre sus películas documentales de las ficcionales, apuntando a una indeterminación2 de su cine, trabajando dentro de los limites de un concepto de cine monstruo3. Por supuesto que la identificación de esta firma trasciende nuestro corpus de análisis en este trabajo, sin embargo, a través de la comprensión de los rasgos característicos de sus documentales de viaje podemos partir a otros rumbos y, por contraste a otras películas suyas, entender de que forma este autor se movió entre diferentes propuestas.

En el camino de encontrar esta firma, me planteo la pregunta, ¿qué es lo que tienen estas cuatro películas de Herzog que las tornan suyas? Me enfocaré en el análisis de la voz en la puesta en escena, e intentaré comprender de qué forma el director se acerca al otro, cómo lo reconoce y habla con él, y sobre él. De qué forma su mirada lo coloca frente al evento presentado y a la otra cultura, y cómo relaciona esas culturas con la suya misma.

A lo que apunto en el presente trabajo es: poder ubicar estas cuatro películas entre una tradición naturalista como propuesta por Paul Rotha y una noción de cine etnográfico, en donde considero radican estas películas de viaje, y a posteriori, la modalidad poética del género documental, sugerida por la taxonomía de Bill Nichols.

Sostengo que entre las cuatro películas en análisis, existen puntos comunes que son de posible identificación y que son observables a la luz de los conceptos sugeridos. Así, estas películas toman elementos de las definiciones clásicas del documental, al mismo tiempo que las transportan a una concepción de un cine contemporáneo.

La noción de viaje me interesa particularmente por la propuesta del dispositivo que presenta dentro del género documental; su modo de filmar una cultura o evento, partiendo de un lugar de incertidumbre personal, en relación a lo que puede ocurrir y a lo que se puede encontrar. Se trata de un cine del contacto físico con el mundo, que tiene en cuenta que la producción y la relación que la imagen establece es única, como mimética del mundo, que "ha estado ahí", y que supone un saber4, aunque esa siempre sea trabajada sobre la mirada autoral. En este tipo de cine se observa el viajar a un lugar con el objetivo de hacer un documental, a pesar del "no saber"5 previo, que obliga a "construir película" mientras se observa y descubre.

Al mismo tiempo que planteo el trabajo, me surge la duda en relación al motivo de este; ¿en qué medida podría tener interés ubicar el cine documental, "de viaje", de este autor entre la tradición y las modalidades? -no tengo tanto interés en la rotulación per se, sino que intento comprender en qué medida es este director transversal, dónde radica su cine, y de qué forma lo talló y fusionó de ahí en adelante. En suma, cómo se transformó a sí mismo, y a este arte a su alrededor, a lo largo del tiempo. 
La importancia de este cineasta reside en su valor central, en la transición entre un cine clásico de propiedades tradicionales, a un cine contemporáneo que arriesgó romper con concepciones preestablecidas, agitando el cine en otros lugares, dejando su huella en la historia de este arte. Este autor siempre tomó una postura irreverente en sus películas, apuntando a obras grandilocuentes, de contornos épicos, rozando el sublime por su acercamiento al mayor absoluto.

Antecedentes Paul Rotha propone su teoría a principios del siglo XX cuando el documental aparece en oposición al cine de ficción. En oposición, entiéndase, colocando cuestiones en cuanto a su valor ético y de puesta en escena, ya que documental y ficción siempre coexistieron.

Para este autor el registro de la "realidad" y el trabajo de temas naturales con materiales naturales, representan un principio constitutivo del documental. En el cine de ficción, por el contrario, se provenía de una puesta en escena teatral, y tenía en su base conceptual el hecho de que la cámara podía capturar los fenómenos fotográficamente en un celuloide sensible, y que eso era posible ampliar y reproducir con un fin comercial. Esto tenía como resultado directo dar más atención a los actores, escenario y trama, que al "método por que se produce su presencia en la pantalla". (Rotha, 1936) Como ejes orientadores de sus teorías, este autor tenía el carácter social y político del documental, la construcción histórica y la denotación del mundo de lo real como materia prima para el "tratamiento creativo de la realidad" (Rotha, 1936).

Rotha denomina sus clasificaciones del documental como tradiciones. Estas corresponden a una época, en la cual existía una voluntad de romper con las concepciones únicas de la ficción, y la voluntad de un acercamiento a lo "real".

Las cuatro tradiciones que propone son: la Naturalista, la Realista, el Newsreel y la Propagandística.

Más adelante desarrollaré sobre la forma como se aplican estas tradiciones al cine de Herzog.

Grierson enumera tres principios, defendiendo la superioridad del documental frente a la ficción, apuntando las cualidades del mundo real, la escena nativa y los actores "originales".

Premisas que, por supuesto, coincidían con las de Rotha en la concepción de sus tradiciones.

Antes de estos autores, todo un conjunto de "formatos" se pueden ubicar dentro de lo que se entendía por documental, pero que no son constitutivos de una historia del género, es decir, corresponden apenas a una expresión pre-documental. El hecho del registro es mencionado por Rotha. Las imágenes cotidianas puramente descriptivas, los films de viaje, algunas de las películas de fines propagandísticos; en resumen, el esfuerzo amateur, que no llega a satisfacer, ni los requerimientos del documental, ni la dramatización creativa de la realidad, ni la expresión del análisis social.

La presencia de noticieros es un punto que, en la teoría de Chanan, evidencia una prehistoria del documental. Nos dice que en las salas de cine francesas y norteamericanas se desarrollan líneas distintivas para el tratamiento de la realidad. Estos documentales primitivos anuncian un cambio en el registro de la historia, particularmente en el escenario de la Primera Guerra Mundial. Esto, según el autor, permitió que el cine se despojase de su "complejo de inferioridad cultural, ya que trascendía el entretenimiento barato para alcanzar 
prestigio patriótico" [Channan, 2007]. En otras palabras, este escenario permitió al cine pre documental entrar en la esfera de la opinión pública.

Para Rotha el noticiero es una tradición que tiene cierta similitud con el documental, esto en la medida en que cada uno lidia a su manera con el material real.

Es Nichols quien más tarde hace una distinción entre un tipo de documental de carácter expositivo, refiriéndose a la modalidad propuesta por él mismo, de las tradiciones noticieras, que para él "constituyen otro ejemplo" (Nichols, 1991). La razón para esto está relacionada con el abordaje ético, y la responsabilidad con los elementos constitutivos del "mundo histórico".

Todos estos autores reconocen a Nanook, el esquimal (1922) como la primera película considerada como documental. Esta pone fin a la prehistoria del género e inaugura la tradición naturalista romántica. Esta película la relacionaré más adelante con el corpus de películas propuesto.

Grierson nos dice también sobre el género documental, que en la época todos los filmes realizados en torno a la naturaleza hacían parte de esa categoría. Era el uso del material natural lo que marcaba la distinción entre ficción y documental. En las situaciones del cine de ficción, sus protagonistas imaginarios estaban superpuestos en los escenarios auténticos alternados con los sets de estudio. Las crisis dramáticas no surgían de las características naturales del ambiente, sino de las inclinaciones y motivos personales de los personajes ficticios. La tradición naturalista, el viaje y la aventura atrajeron por otro lado, fotógrafos y entusiastas independientes. Lo que sería una: Evolución que va del uso de los exteriores en el film teatral, la épica del western y el travelogue, a las observaciones simples de las personas [...], y así a Flaherty y su tema idílico romántico del hombre en lucha con la naturaleza en los lugares remotos del mundo moderno. (Rotha, 1936).

También los conceptos de cine etnográfico, en el sentido de la antropología visual, podrían ser considerados antecedentes de este cine de Herzog. En su búsqueda se propone ir a los lugares alejados del occidente, en el intento de se acercar al otro, relacionando su propia cultura con la de las personas allí presentes. Poniendo énfasis en la exploración de la naturaleza de un fenómeno social concreto, sin intentar una explicación sobre ello, centrándose en un pequeño grupo social de personas, y interpretando él mismo los significados simbólicos en pantalla, sin intentar un análisis descriptivo. Por otro lado Herzog nunca intentó ser el observador etnográfico común, que coloca su cámara en escena esperando el despliegue de las acciones, sin actuar sobre ellas, el siempre insistió en "dirigir" sus películas, en criar personajes, aunque estos no lo sepan todavía en el momento del rodaje, la forma como estos los tratará en la película, normalmente a través de la utilización de la voz.

Más aun, Herzog se opone personalmente a las líneas francesas del cinema vérité6, y del cine directo en su vertiente norte-americana, que proponían el "realismo" del cine al mismo tiempo que la expresividad autoral. En suma, estas películas son antropológicas en el sentido que van al encuentro del "otro", pero no en la forma y momento de la observación.

Análisis de películas

Fata Morgana (1971) es una película que hace notar la presencia del director en el lugar alejado del mundo moderno occidental. Toda la película narra poéticamente el lugar desierto, la no existencia de vida, que 
progresivamente se vuelve humana, en su paisaje, con los destrozos de la guerra, en los sonidos y en la representación de la muerte. Presentando una estructura tripartita, la película avanza desde el aislamiento completo, al encuentro con las personas presentes en ese lugar. Estas raramente son locales, autóctonas, y cuando lo son, no hablan de sí o por sí mismos. Es decir, los personajes "naturales" no se expresan en la película, no de forma comprensible para el espectador. Son sí, más bien, elementos representantes del lugar y que "ilustran" el paisaje. Los personajes a los que se les ha conferido palabra, son los propios compatriotas del realizador, alemán-parlantes ahí presentes.

Representan lo que él mismo conoce, su propia búsqueda personal, de su identidad y cultura, en el lugar desconocido.

El planteo de la voz, la narración longa que se mantiene a lo largo de toda la película, da cuenta de lo que para él son esos paisajes, la "visión" de la creación en su estado puro, onírico, tocando el sagrado. En las películas de este autor la marca de lo sublime, como definido por Burke, se mantiene en diversos ejemplos.

En el año de 1977 realiza La Soufrière - A la espera de una catástrofe inevitable. Esta relata la historia de una isla en América Central, en las Antillas francesas, llamada Guadalupe, donde el volcán principal presenta evidentes señales de erupción y donde casi todos los habitantes se escaparon, dejando la isla desierta. Herzog llega con un equipo de camarógrafos al local del incidente, preparado para filmar una catástrofe que termina no ocurriendo.

Las referencias que hace a la situación global, en el verano de ese año, de varios puntos del planeta que temblaban, contextualizan el evento y da las primeras señales de la magnitud de la explosión esperada, comparada con la fuerza de cinco o seis bombas atómicas.

La voz en la película habla desde la experiencia personal, al mismo tiempo que extrae elementos del mundo histórico que sirven como marcos referenciales. Dice, "el evento me fascinó inmediatamente cuando leí en el periódico que un único campesino pobre que vivía sobre las laderas del volcán se negaba a partir". Así llega a Base-Terre al día siguiente, al extremo sur de la isla, un pueblo en la zona de peligro. Desde su observación denota señales que le llaman la atención, elementos que no cuentan necesariamente "historia", sino que sirven como refuerzo de su presencia ahí, narran lo que él ve. Refiere en un momento: "La explosión parecía más cercana y los científicos habían huido". Mientras enseña imágenes captadas de helicóptero, describe su sensación de estar presenciando "las ultimas horas de existencia de aquél lugar y de estar filmando las últimas imágenes que se rodarían de aquella ciudad". Aquí vemos como, al igual que en las otras películas en análisis, se trata el tema desde la inminencia de fin del lugar o de la cultura ahí existentes, y que él filma por necesidad de preservar.

En un momento el director aparece en cuadro, apuntando a las nubes de gases tóxicos mortales que se acercan por el aire. Esta puesta en escena es simbólica de una determinación ética de su parte, tanto para con el público como para con su equipo, siendo que se arriesga él mismo antes que sus compañeros para contar esa historia, que necesita ser registrada por última ocasión.

Hay una tensión constante en su narración y en la utilización repetida de la palabra "miedo". 
También a través de este recurso, el director está constantemente llevando al espectador a ese escenario de incertidumbre y posibilidad de muerte, donde el volcán explotará en su potencia de proporciones épicas.

En un momento de la película admite la no-erupción del volcán como un fallo, y sus últimas palabras son sus propios sentimientos en relación a la experiencia, que caracteriza de "carácter patético".

También las películas Wodaabe - Pastores del sol y Jag Mandir, anteceden el fin de algo, de una cultura y su inminente amenaza de destrucción, y la póstuma necesidad personal en relatar eso. Podría decir que Herzog se auto impone un cierto "deber" frente a situaciones que requieren solución, aunque se muestre resistente a las interpretaciones ideológicas que le puedan ser atribuidas. Desarrollaré este tema más adelante en el trabajo.

Wodaabe, cuenta la forma de vida de un pueblo nómade en el desierto africano, entre Níger, Mali y Burkina Faso. La escasez de agua y recursos torna la vida en este lugar inhóspito muy difícil, colocando así la cultura de estos individuos en posición de posible extinción.

Al mismo tiempo, Herzog resalta constantemente las características de belleza de esta tribu, sus rituales exóticos, todo lo auténtico que se puede perder si esta tribu desaparece o se ve forzada a buscar otra forma de vida.

Jag Mandir es otra película sobre una cultura que se desvanece en el olvido. Un Maharana hindú, dueño de vastas propiedades y un castillo magnífico, construido encima del agua y en riesgo de hundirse con el tiempo, teme por el desaparecimiento de su cultura y convoca un gran festival para celebrarla. Manda a llamar artistas de todos los lugares de India y hace una ceremonia de varios días, donde son demostradas las más diversas formas de expresión de su cultura. Herzog está en el lugar, convocado por el propio anfitrión, y filma el festival, la belleza de los cuerpos en sus movimientos fantásticos, al mismo tiempo que narra en voz off lo que a la brevedad se habrá extinguido para siempre.

En las dos ultimas películas observadas Herzog se encarga casi por completo de la narración voz en off. Existen momentos largos de contemplación de los rituales, momentos en que la música de fondo acompaña los eventos tejiendo el nivel dramático, pero en estas, el director nunca abandona totalmente la narración de lo que él mismo ve, su presencia extranjera en estos lugares, ya que rara o ninguna vez confiere la palabra a los intervinientes.

Entre la tradición naturalista, el carácter etnográfico y la modalidad poética

La tradición naturalista, tal como el newsreel, en el sentido determinado por Paul Rotha, proponían ya el espíritu aventurero de la búsqueda ultramarina, por los lugares desconocidos y exóticos, sobre los cuales el público deseaba saber. Flaherty es el primer documentalista "romántico", el primer con la sensibilidad en su mirada para captar de forma plena los modos de vida de las personas en su lugar "natural". Esto fue visible en su película Nanook, el esquimal (1922). Este es uno de los directores que viene de la línea de los antecedentes exploradores, que buscaban el mundo alejado del occidente, para traerlo en forma de películas. Lo que lo distingue de los anteriores documentalistas, es entonces, su mirada sensible.

Lo que pretendo en la primera parte de esté tópico es establecer la ligación entre estos primeros documentalistas románticos, y las cuatro películas de "viaje" que analizo. Al mismo tiempo que intento establecer 
esta relación, que intento acercar estos autores, un impulso me aleja en la dirección contraria. Es decir, Herzog se distancia del modo de hacer cine presente en Nanook al mismo tiempo que guarda elementos de esta.

¿Qué sería entonces lo que existe en común entre las cuatro películas propuestas en el corpus de análisis y la de Flaherty? Sin duda que, el deseo de viaje, de traer ese mundo distante al occidente, y su espíritu de aventura, su mirada romántica de quien parte al desconocido para intentar acercarse al otro, comprenderlo, y traer el "retrato" de su cotidiano.

La escuela inglesa propone una mirada ética sobre el documental, al mismo tiempo que "creativa". Las películas que llegaban eran usadas como formas de dar a conocer los escenarios y sujetos "naturales", en un formato que suscitaba más curiosidad que propiamente aspiración a mirarlos de cerca, estableciendo la relación constante, "ellos y nosotros". Ya Trinh Minh-ha, referida por Catherine Russel en su libro Experimental Ethnography, The work of Film in the Age of Video, criticaba el film etnográfico, por su concepción dividida del, "ellos allá" (los sujetos de la etnografía) y "aquellos acá" (en el cine, mirándolos). Más que intentar un acercamiento al otro desde las miradas antropológicas, del cinema vérité y del cine directo, Herzog tiene un deseo genuino en ver al otro desde la diferencia, para él se trata de imponer su mensaje sobre lo que es mostrado en pantalla, se trata de dirigir actores y crear situaciones para que, desde su posición presente, pueda construir ese "otro", sin lo idealizar, sino para que lo podamos ver en su problemática concreta: “... no se trata tanto de una pasión por lo exótico como de una búsqueda de lo extraordinario en lo ordinario" (González, 2013). Contrasta las culturas ahí presentes con la suya al extremo, llegando a dominar toda la narración y el mensaje de la película por completo. Desde su lugar apunta concretamente a la diferencia y al peligro inminente, en el intento de generar preocupación social sobre el tema. Y este es, diría, su gesto ético. Estas películas son, en este sentido, divergentes a las de la tradición naturalista, solo quedándoles en común el espíritu aventurero y los elementos "naturales" con que trabajan.

Al mismo tiempo, los elementos que lo alejan de la tradición naturalista son los que lo acercan al documental contemporáneo, y la modalidad poética propuesta por Bill Nichols, es la que considero más pertinente para verificar esto mismo. Tal como lo reconoce Nichols, ninguna película está completamente inserta en una sola modalidad. Estas son películas que arman su propio dispositivo, proponen una mirada propia y crean códigos singulares. Esto es justamente lo que me interesa apuntar, la dispersión intrínseca presente en cada una de estas películas (y por lo general en su obra), que las torna imposibles de categorizar por completo, sobrando apenas algunos elementos comunes, que son objeto del presente análisis.

La modalidad poética es definida por Nichols como una que adviene de las miradas modernistas y del avantgarde del periodo post Primera Guerra Mundial. En este momento histórico se encuadran tanto la vida como el cine de Herzog, en suma, su contexto cultural del llamado Nuevo Cine Alemán.

Nichols caracteriza esta modalidad como: Particularmente adepta a abrir posibilidades, formas de conocimiento alternativas, en vez de transferir información de modo directo. Persigue un argumento o punto de vista particular, o presenta un problema que necesita solución. Esta modalidad transmite tono y afecto mucho más que presentar conocimiento o intentar persuadir7.

El material histórico es retirado del mundo filmado y transformado en algo distinto. En estas películas, su narración juega justamente con eso, con la transformación del material según su interpretación. Con el tono de 
voz personal, comunicando preocupación, y más que eso, un "deber” en enseñar el problema y direccionar la preocupación hacia un lugar de cuidado.

Nos refiere todavía Nichols acerca de esta modalidad: "La modalidad poética tiene muchas facetas, pero todas ellas enfatizan la forma en que la voz del realizador agrega al mundo histórico fragmentos formales y estéticos, particulares del film en sí"8.

“...quiebra la línea temporal y espacial en perspectivas múltiples, negando coherencia a las personalidades [...] Los actores sociales raramente encarnan una forma psicológicamente compleja con carácter, o con una idea fija del mundo"9.

Los personajes son normalmente utilizados como elementos ilustradores del mundo histórico que los involucra. Nunca les es completamente cedida la palabra, sino para que ellos ilustren lo que el director quiere comunicar. No se tornan nunca personajes centrales, dotados de carácter complejo, sobre los cuales sería construida una historia o trama.

\section{Conclusiones}

Hay en Herzog el espíritu aventurero romántico, del viaje y de la búsqueda, a través de la utilización de los materiales "naturales" y la escena nativa en los lugares alejados del mundo occidental, y que él transforma por la puesta en escena de los elementos y a través de la narración voz en off, vinculadora de eventos. Hay también en sus películas la mirada ética, característica de las propuestas inglesas, aunque sea planteada de modo distinto: desde el contraste entre las culturas y la postura personal. Herzog no intenta una exotización de esos lugares, sino que apunta al extraordinario allí espejado, el fuera de común, el punto culmine de esa situación, que representa ese evento o cultura en sí mismo, y que, por lo general en estas películas, a la brevedad no existirá más, siendo este muchas veces el problema concreto que necesita solución. Es crudo en la forma como "ve" y relata, tal vez, fruto de esa amargura presente en la inminencia del fin. Esa es su forma de expresarse éticamente; alertando conciencias, de alguna forma, y a través de su trabajo, intentando alcanzar el público con una preocupación social. Al mismo tiempo, él mismo no se permite rotular demasiado a una ideología. Para él, existe un "deber ser" de su trabajo, como lo refiere en la película de Les Blank, Burden of Dreams (1982), realizada mientras dirigía Fitzcarraldo (1982) en la selva amazónica. Algo personal lo mueve, más que un querer "cumplir" un deber social público. Sus "visiones", las paisajes soñadas que intenta imprimir en pantalla, esas son sus "musas", las que lo mueven. En este sentido Herzog es un autor en cierta medida aislado. Es un director irreverente y polémico. Que propuso películas de difícil concretización humana, en los lugares más inhóspitos. Y en las cuales, por veces, y en situaciones más grandes que su propia voluntad y poder personal, personas osaron sus propias vidas.

Más allá del corpus sugerido en este trabajo, podemos observar que este autor propone variados dispositivos en las películas que va realizando a lo largo de su carrera. Cuando cuestionado sobre conexiones específicas entre al menos algunas de ellas, contesta refiriendo a los personajes presentes. Afirma sobre ellos que "pertenecen a la misma familia, independientemente de que sean ficcionales o no". Sobre sus películas en general nos dice, "todas [...] expresan una manera similar de sentir la vida, y por eso conforman un todo" (Cronin, 2014, p. 83). Sus películas tienen elementos comunes, como la utilización de animales, o el hecho que Herzog se niegue a filmar en estudios, porque, según él mismo, ahí "no hay escenarios naturales" (Cronin, 2014, p. 121). 
Este autor trabaja tanto en ficción como en documental, y a veces entre los dos géneros, dando cuerpo tanto a un cine híbrido como a un cine complejo e indeterminado. Es decir, según la definición propuesta por Bernini, "la relativa indiferencia entre lo documental [...] y lo ficcional". Esta indeterminación va más allá de la hibridación, que supone apenas la mezcla y no la fusión de los géneros, donde ambos son identificables. La indeterminación presenta así, un "problema de acceso al conocimiento del mundo" (Bernini, 2012, p. 1).

Su cine podría también por estas razones ser dicho "monstruo", tal cómo lo apoda Jean-Louis Comolli, en Ver y poder. Nos dice, El cine nasció monstruoso. Un arte impuro, decía Bazin. [...] En la errancia de esta confusión inicial con la energía que le es propia, el cine devora sus fronteras. Habitualmente se distingue entre cine documental y cine de ficción, se los opone, se los fija en géneros determinados. [...] esta distinción es a menudo contradicha tanto en el sistema de obras cuanto en la práctica de los cineastas [...] en su deseo. [...] lo más vivo de la energía cinematográfica circula entre los dos polos opuestos de la ficción y del documental para entrecruzarlos, entrelazar sus flujos, hacerlos rebotar el uno en el otro. Corrientes contrariadas de las que resultan bellos cine-monstruos.

(Comolli, 2007, p. 212).

Su cine intenta también constantemente alcanzar el ideal sublime, en su búsqueda por un Mayor, entre el peligro y el acto de fe.

Según Edmund Burke nos refiere sobre lo sublime: Todo lo que sea de algún modo capaz de incitar ideas de dolor y peligro, es decir, todo lo que sea de alguna manera terrible o relacionado a objetos terribles o actúa de un modo análogo al terror constituí una fuente de lo sublime, es decir, produce la más fuerte emoción de que el espíritu es capaz.

(Burke, 1993) En conclusión afirmaría que; a pesar de la diversidad de los dispositivos propuestos en estas películas, pueden identificarse en ellas elementos comunes, cómo observo a lo largo de este trabajo. Y es en los elementos comunes justamente (personajes "nativos" y escenarios "naturales", el acercamiento al "otro" por la mirada autoral, los elementos de la modalidad poética en la puesta en escena de la voz, la búsqueda de lo extraordinario en el cuotidiano, y el acercamiento al sublime), donde, a pesar de la fluctuación del dispositivo (documental, ficcional, etnográfico), se puede encontrar una firma herzogiana.

\section{Notas}

1. Referencia al concepto utilizado por el propio Herzog (Cronin, 2014, p. 53).

2. Referencia al concepto presentado por Emilio Bernini, 2012.

3. Referencia al concepto propuesto por Jean-Louis Comolli en Ver y poder, 2007.

4. Como referido por Philipe Dubois en El acto fotográfico.

5. Referencia al concepto de Jean-louis Comolli, en Ver y poder, 2007.

6. Ver Declaración de Minnesota. Verdad y hechos en el cine documental, 1999. 
7. Nichols, Bill, Introduction to Documentary. Bloomington: Indiana University Press, 2001. p. 103.

8. Ibid. p. 105.

9. Ibid. p. 103.

Bibliografía

Nichols, B. (1997). La representación de la realidad, cuestiones y conceptos sobre el documental. Buenos Aires: Paidós.

Nichols, B. (2001). Introduction to Documentary. Bloomington: Indiana University Press.

Shaeffer, J. M. (1990). La imagen precaria del dispositivo fotográfico. Lavel: Ediciones Cátedra.

Dubois, P. (1986). El acto fotográfico, de la representación a la recepción. Paidos Iberica Ediciones.

Rotha, P. (in collaboration with Sinclair Road y Richard Griffith) (1936). Documentary Film, The use of the film médium to interpret creatively and in social termis the life of the people as it exists in reality. Londres: Faber and Faber.

Grierson, J. (2014). Postulados del documental. Disponible en:

http://www.catedras.fsoc.uba.ar/decarli/textos/Grierson.html Chanan, M. (2007). The Politics of Documentary. Londres: British Film Institute.

Herzog, W. (1999). Declaración de Minnesota. Verdad y hechos en el cine documental. Walker Art Center, Minneapolis, Minnesota.

Comolli ,J. L. (2007). Ver y poder: la inocencia perdida: cine, televisión, ficción, documental. Buenos Aires: Aurelia Rivera: nueva librería.

Cronin, P. (2014). Herzog por Herzog: entrevistas y edición de Paul Cronin. Ciudad Autónoma de Buenos Aires: El cuenco de plata.

González, L. (2013). Werner Herzog: El Documental como indagación fenomenológica. Revista Questión, Vol. 1, No 40, Octubre - Diciembre 2013. La Plata: Universidad Nacional de La Plata.

Bernini, E. (2012). Territorios audiovisuales, Cine video, televisión, documental. Instalación, nuevas tecnologías, paisajes mediáticos. Jorge La Ferla y Sofía Reynal, (comp.). Buenos Aires: Libraria.

Russel, C. (1999). Experimental Ethnography. Durham and London: Duke University Press. Burke, E. 1729-1797, Uma investigação filosófica sobre a origem de nossas idéias do sublime e do belo; Tradução, apresentação, notas: Enid Abreu Dobránszky. - Campinas, SP : Papirus : Editora da Universidade de Campinas, 1993.

Filmografía 
Flaherty, R. (1922). Nanook, el esquimal. Disponible en: https://www.youtube.com/watch?v=_f8J9NRchOE Herzog, W. (1971). Fata Morgana.

Herzog, W. (1977). La Soufrière - Warten auf eine unausweichliche Katastrophe.

Blank, L. (1982). Burden of Dreams.

Herzog, W. (1989). Wodaabe - Herdsmen of the sun.

Herzog, W. (1991). Jag Mandir.

Abstract: Four films by the german director Werner Herzog are analyzed as travel film essays. These works, less known, short films, that are supposed to risk less, or in other words, those works of physical research of documentary creation in the very action of observation illustrates a personal tour through more conventional ways to make documentaries. This article argues that, on one hand, in these movies the author applies a staging that comes from Paul Rotha's naturalism and his romantic device; and on the other hand, that what Herzog adds is neccesarily what moves them away from a container definition. The value of these film essays lies in the use of the classic tools with new meanings given by the author. In this article we reflect about the trouble in detect patterns in documentary cinema after the case-study of one author's filmography.

Key words: Werner Herzog - trip documentaries essays - Fata Morgana - La Soufrière - Wodaabe - Jag Mandir.

Resumo: Quatro filmes do diretor alemão Werner Herzog são analisados por suas características comuns como ensaios fílmicos de viagem. Estas obras, menos conhecidas, meiometragens, que procuram fazer documentais no ato mesmo de observação, servem para ilustrar seu percurso pessoal pelas formas de fazerem documentais mais convencionais.

Este artigo afirma, por um lado, que nestes filmes o autor faz uma posta em cena tomada do naturalismo de Paul Rotha e seu dispositivo romântico, entre outros autores, e, por outro, que aquilo que agrega Herzog é necessariamente o que as separa de uma definição inclusiva. É dizer, para nós, o valor destes ensaios fílmicos está no uso das ferramentas clássicas que são re-significadas pela marca autoral. Neste artigo, se reflete sobre a dificuldade em determinar modalidades e fechar filmes em definições, no cinema documental, partindo do estudo de casos de um recorte da filmografia de um autor.

Palavras chave: Werner Herzog - ensaios fílmicos de viagem - Fata Morgana - La Soufrière - Wodaabe - Jag Mandir.

Werner Herzog, documentales de viaje: Fata Morgana, La Soufrière, A la espera de una catástrofe inevitable, Wodaabe, Pastores del sol, Jag Mandir fue publicado de la página 17 a página27 en Cuadernos del Centro de Estudios de Diseño y Comunicación $\mathrm{N}^{\circ} 62$ 